\title{
The dawn of the liquid biopsy in the fight against cancer
}

Review

\author{
Irma G. Domínguez-Vigil ${ }^{1}$, Ana K. Moreno-Martínez ${ }^{1,2}$, Julia Y. Wang ${ }^{3}$, Michael H. \\ A. Roehrl ${ }^{4}$ and Hugo A. Barrera-Saldaña ${ }^{1,5}$ \\ ${ }^{1}$ Departamento de Bioquímica y Medicina Molecular, Facultad de Medicina de la Universidad Autónoma de Nuevo León, \\ Monterrey, Nuevo León, México \\ ${ }^{2}$ Genetics Laboratory, Vitagénesis, Monterrey, Nuevo León, México \\ ${ }^{3}$ Curandis Laboratories, New York, NY, USA \\ ${ }^{4}$ Department of Pathology, Memorial Sloan Kettering Cancer Center, New York, NY, USA \\ ${ }^{5}$ TecSalud, Tecnológico de Monterrey, San Pedro Garza García, Nuevo León, México \\ Correspondence to: Michael H. A. Roehrl, email: roehrlm@mskcc.org \\ Hugo A. Barrera-Saldaña, email: habarrera@gmail.com
}

Keywords: liquid biopsy; cfDNA; ctDNA; early detection; diagnostics

Received: October 17, 2017

Accepted: November 10, 2017

Published: December 08, 2017

Copyright: Domínguez-Vigil et al. This is an open-access article distributed under the terms of the Creative Commons Attribution License 3.0 (CC BY 3.0), which permits unrestricted use, distribution, and reproduction in any medium, provided the original author and source are credited.

\section{ABSTRACT}

Cancer is a molecular disease associated with alterations in the genome, which, thanks to the highly improved sensitivity of mutation detection techniques, can be identified in cell-free DNA (cfDNA) circulating in blood, a method also called liquid biopsy. This is a non-invasive alternative to surgical biopsy and has the potential of revealing the molecular signature of tumors to aid in the individualization of treatments. In this review, we focus on cfDNA analysis, its advantages, and clinical applications employing genomic tools (NGS and dPCR) particularly in the field of oncology, and highlight its valuable contributions to early detection, prognosis, and prediction of treatment response.

\section{INTRODUCTION}

The U.S. National Cancer Institute (NCI) defines liquid biopsy (LB) as "a test done on a sample of blood to look for cancer cells from a tumor that are circulating in the blood or for pieces of DNA from tumor cells that are in the blood" [1]. In this review, we will primarily focus on the second part of this definition, i.e., the detection of circulating DNA.

The first steps to explore the potential of cell free DNA for genetic testing of cancer were made in 1948, when the first publication of cell-free DNA (cfDNA) and free RNA circulating in human blood appeared [2]. Fast forwarding to today shows that numerous tests based on circulating nucleic acids are in development that - so is the hope - will help to opportunely discriminate patients with cancer from healthy individuals [3] (Figure 1).

In its beginnings, the application of LB did not generate much attention on the part of the scientific community. A review of the PubMed (NCBI) database, using the search term "liquid biopsy" from 1975 onwards, shows a recent increase in the number of publications, denoting rapidly growing interest in LB (Figure 2).
Rediscovering LB for diagnostic purposes

To the surprise of many, Osborne et al. reported in 2013 the case of a 37-year-old pregnant woman with a normal medical history but a non-invasive prenatal testing (NIPT) result suggestive of aneuploidy for chromosomes 18 and 13. NIPT searches for fetal cfDNA (3-13\%) among the maternal cfDNA [4]. After spontaneous labor, a male fetus was born without dimorphic characteristics. The patient's vaginal biopsy revealed a small cell carcinoma with evidence of aneuploidy in $80 \%$ of analyzed cells, including alterations in chromosomes 18 and 13 that were consistent with the NIPT test performed previously. This was the first reported case of detection of cancer in a pregnant women by cfDNA [5].

\section{Genome alterations of cancer}

Cancer is a pathological condition that encompasses more than 100 distinct disease entities with diverse risk factors and epidemiologic features and that can originate from essentially all cell types and organs of the human body. It is characterized by 
a relatively unrestrained proliferation of cells that can invade beyond normal tissue boundaries and metastasize to distant organs [6]. A hallmark of cancer is alterations in the genome. These alterations may be single nucleotide variants (SNVs), promoter methylation, copy number variation (CNVs), chromosomal structural rearrangements, and alterations in sites relevant for transcription, splicing, RNA maturation, or translational efficiency [7].

The International Cancer Genome Consortium (ICGC) and The Genomic Atlas of Cancer (TCGA), which aim to catalog the genomic information of the various types of cancer and foster discoveries that could allow better understanding of cancer origins and development [8], have carried out large-scale research into many different types of cancers in order to determine the genomic signatures of each. For example, mutations in the genes ERBB2, PIK3R1, TP53, and NF1 stand out in glioblastoma [9]; TP53, NF1, BRCA1, BRCA2, RB1, GABRA6, CSMD3, FAT3, and CDK12 alterations characterize ovarian cancer [10]; TP53, PTEN, CTNNB1, PIK3CA, ARID1A, KRAS, ARID5B, and POLE mutations are features of endometrial cancer [11]; TP53, RAS, EGFR, BRAF, PIK3CA, MET, RIT1, STK11, KEAP1, NF1, RB1, CDKN2A, SETD2, ARID1A, SMARCA4, $R B M 10, U 2 A F 1$, and $M G A$ are hallmarks of lung cancer [12]. These studies were made possible with next generation sequencing (NGS) technology that has the advantage of simultaneously analyzing a large number of genes related to a specific phenotype, allowing the identification of mutations that are otherwise not easily detected [13]. One of the main advantages of NGS is that it allows global determination the molecular subtype of the disease (via large gene panel, exome, or even whole genome sequencing). It also makes monitoring progression of the disease and assigning targeted molecular therapies easier [8].

\section{Liquid biopsy in cancer}

Cancer is often found in organs or tissues of the body that are difficult to access, such as brain, ovaries, or pancreas. Thus measurements of tissue-resident biomarkers for such cancers may be difficult or associated with significant clinical risk, such as bleeding or infection as consequence of an invasive biopsy or excisional procedure [14].

Surgical biopsies (SB) continue to dominate as the "gold standard" for diagnosis and choice of treatment for diseases of genetic and contagious origin. However, they also present disadvantages. Among them is the fact that tumor tissue sampling delivers only a static and spatially limited representation from the time of the surgical procedure. Cancers, however, vary over time due to continuous changes that result in genetic heterogeneity within the tumor and between the primary and metastatic sites (a characteristic typical of cancers in advanced stages). In addition, the majority of biopsies are commonly fixed in formalin and embedded in paraffin for routine pathology, which can reduce their utility for advanced molecular analyses [15]. Some of these disadvantages can be addressed with the implementation of LB.

LB holds great promise for detection, prognosis, and prediction of response to cancer treatment [16-18]. Among the main sources of LB-based biomarkers are circulating tumor DNA (ctDNA), circulating tumor cells (CTCs), exosomes, and microRNAs. ctDNA currently leads applications for diagnostic purposes, and, for this reason, it is the main subject of this review.

While we do not anticipate that LB will fully replace or directly compete with SB for most diagnostic purposes any time soon, we do very much foresee that LB will complement SB rapidly within the next 3-5 years and will become a tool of choice for dynamic monitoring of patients on treatment or under active surveillance. In

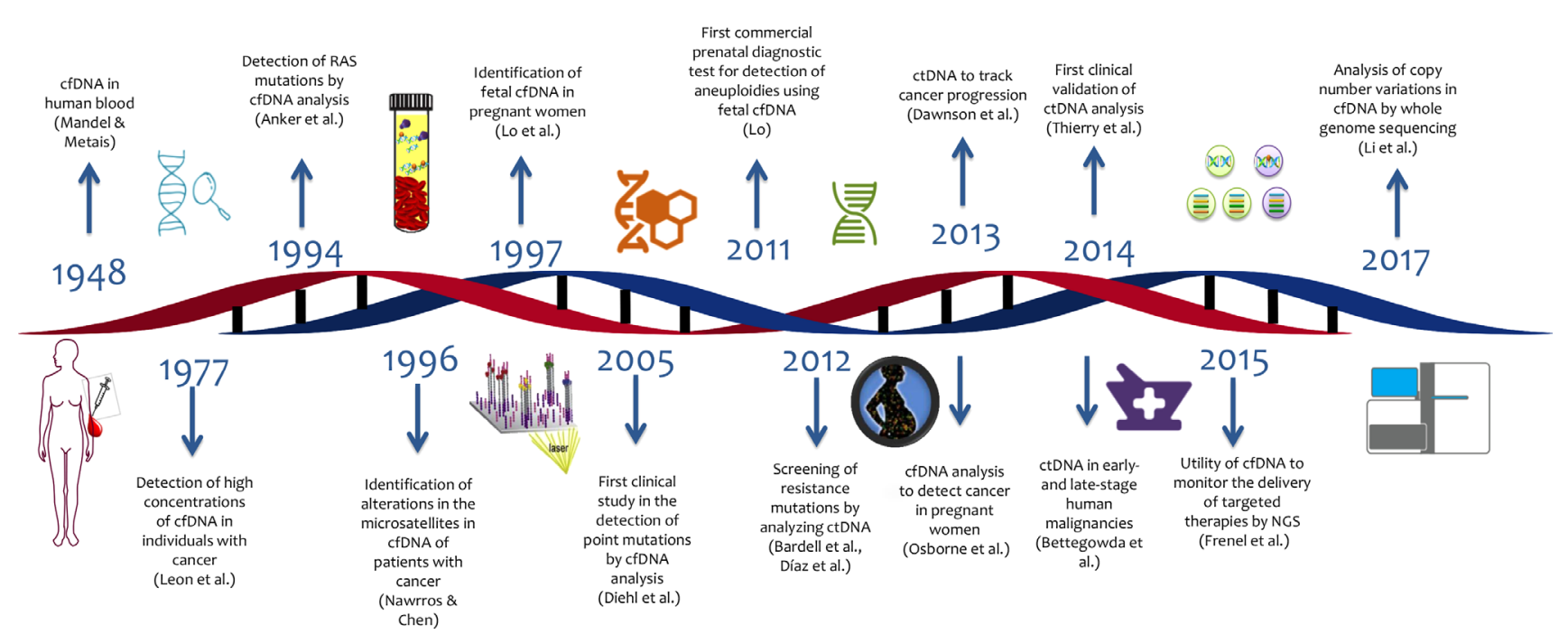

Figure 1: Timeline of liquid biopsy development. 
many instances, LB will also prompt further imaging workup and/or re-biopsy of tissue lesions. A frequently cited advantage is that obtaining LB fluids is much less invasive than SB or even imaging studies [19]. Scientific studies have increasingly provided evidence of the utility of LB for early diagnosis. ctDNA has been detected in up to $75 \%$ of pancreatic, ovarian, colorectal, bladder, breast, neck, hepatocellular, and gastroesophageal cancers and melanomas and in up to $50 \%$ of primary $\mathrm{CNS}$, renal, prostatic, and thyroid cancers [17]. It has also been associated with metastatic burden in patients with nonsmall cell lung cancer (NSCLC) and small cell lung cancer (SCLC), among other tumors [19].

LB has thus, a wide potential of clinical applications and affords physicians a new tool for clinical management of difficult to treat patients with advanced stage cancers, prediction of treatment response, detection of recurrence, and traceability of tumor genome evolution over time $[20,21]$. Studies demonstrate that ctDNA can be used in the routine management of lung cancer to monitor clonal evolution and identify treatment resistance $[19,22]$, particularly in patients with NSCLC who are treated with specific tyrosine kinase inhibitors (TKIs, such as gefnitinib, erlotinib, crizotinib, and ceritinib) [19]. Nearly half of NSCLC patients acquire resistance to TKIs and present EGFR T790M mutations; consequently, a second biopsy is required. Indeed, the European Society for Medical Oncology (ESMO) suggested LB as an alternative to tissue re-biopsy and presented LB as a validated method for monitoring progression of EGFR mutated patients [23, 24].

Figure 3 contrasts some of the advantages of LB relative to SB. LB can meaningfully augment SB by potentially sampling tumor heterogeneity more comprehensively and by revealing the dynamics of molecular changes of cancer cells while the patient is undergoing treatment [21].

LB has thus a wide potential of clinical applications and affords physicians with a new tool for clinical management of difficult to treat patients with advanced stage cancers, for prediction of response to treatment, for detection of recurrence, and for traceability of tumor genome evolution over time [20, 21].

\section{Circulating tumor DNA (ctDNA)}

DNA is continuously released in fragments into the circulation through processes such as apoptosis and necrosis by both normal and cancerous cells [21, 25-27]. When released irrespective of cell of origin, it is typically referred to as cfDNA (cell-free DNA); but when released specifically by cancer cells, it is mostly referred to as ctDNA (circulating tumor DNA). Among the molecular characteristics of ctDNA are that it may harbor mutations, CNVs, methylation changes, or integrated viral sequences associated with the tumor [28-32]. ctDNA is mainly found in plasma and serum; however, it can also be isolated from ascites, breast

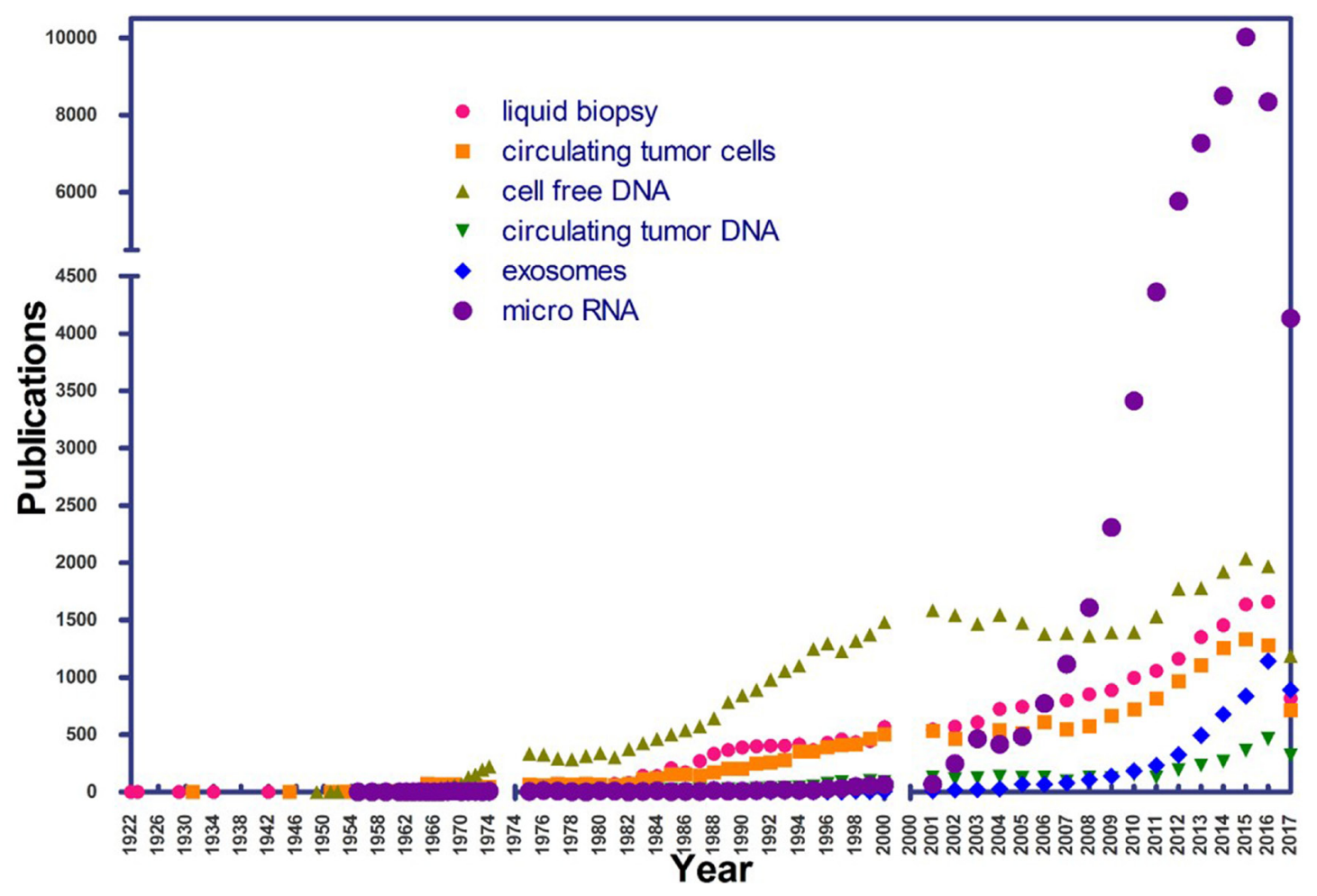

Figure 2: Number of publications per year in PubMed, using the terms "liquid biopsy", "cell free DNA", "circulating tumor DNA", "exosomes", "micro RNA", and "circulating tumor cells" as of July 1, 2017. 
milk, lymphatic and peritoneal fluids, bone marrow aspirates, urine, prostatic fluid, peritoneal lavage, sputum, cerebrospinal fluid, gastric juice, and biliary and even stool samples [33]. Circulating nucleic acids are removed from the blood by the liver and kidney and have variable circulating half-lifes ranging from 15 minutes to several hours $[27,34]$. The concentrations of this genetic material in patients with cancer range from 0 to $1,000 \mathrm{ng} / \mathrm{mL}$ of blood, with an average of $180 \mathrm{ng} / \mathrm{mL}$. In contrast, cfDNA in healthy subjects ranges from 0 to $100 \mathrm{ng} / \mathrm{mL}$ of blood, with an average of $30 \mathrm{ng} / \mathrm{mL}$ [27]. As a reference, a patient with a tumor burden of $100 \mathrm{~g}$ released $3.3 \%$ of ctDNA into the circulation [35].

In colorectal cancer, it has been found that ctDNA is more sensitive than the detection of serum protein biomarkers such as carcinoembryonic antigen (CEA), showing tighter changes in response to tumor resection and a greater predictive capacity for recurrence. In 2014, Bettegowda et al. [36] detected mutations in the KRAS gene of plasma ctDNA in a group of 206 patients with colorectal cancer, with a sensitivity of $87.2 \%$ and a specificity of $99.2 \%$.

\section{Other source of LB-based biomarkers}

\section{Circulating tumor cells (CTCs)}

CTCs have been discovered for Asworth in 1869 during an autopsy of a patient who had metastatic cancer [37]. They are cancer cells that detach from a primary or metastatic tumor site and are present in the circulation. Clinical evidence indicates that patients with metastases have 1-10 CTCs per $\mathrm{mL}$ of blood and they are rarely found in clinically healthy people or in people with nonmalignant tumors. CTCs have been detected in different types of cancers, such as breast, ovarian, prostate, lung, colorectal, hepatocellular, pancreatic, head and neck, bladder, and melanoma [38]. There are commercial systems for their detection and isolation, of which the most used is the CellSearch ${ }^{\circledR}$ system, an automated detection system for CTCs that uses anti-EpCAM antibodies, anti-CK antibodies, and anti-CD45 antibodies. CTCs are associated with a poor prognosis and are predictive of shorter progression-free survival and overall survival in patients treated with metastatic breast, colorectal, or prostate cancers who have CTC counts of $\geq 5, \geq 3$, or $\geq$ 5 , respectively, per $7.5 \mathrm{~mL}$ of blood at any time during the course of the disease [39-41]. However, CTCs are often not detectable in patients with dysplastic or early malignant lesions, thus limiting their utility for early diagnosis or surveillance [42]. Besides their detection and isolation, CTCs can be cultured in vitro and to expand ex vivo for further analyses [43-46].

\section{Exosomes}

Exosomes are small round vesicles, 30-120 nm in diameter, and of endosomal origin carrying RNA,
miRNAs, DNA, and proteins that are released by multiple cell types (including tumor cells) into the extracellular environment. Exosomes may mediate some form of communication between cells, being internalized by other cells $[42,47,48]$. They are found in biological fluids like blood, urine, saliva, pleural effusions, amniotic fluid, nasal secretions, bronchoalveolar lavages, cerebrospinal fluid, breast milk, and ascites [49-51]. Special features of exosomes have been associated with several types of cancer, such as pancreatic [52, 53], breast [54], gastric [55] colon [56], and ovarian [57].

\section{miRNAs}

MicroRNAs or miRNAs are small molecules of non-coding RNA, between 19 and 24 nucleotides in length, that act as regulatory molecules of gene expression, exerting function by hybridizing to inhibit the translation of mRNAs of its target genes [58-60]. Differential expression of miRNAs in patients with cancer has been described. miRNAs like those of the Let-7 family have been associated with lung cancer $[61,62]$; miR15a/ miR16a with chronic lymphocyte leukemia [63]; miR-34 family to neuroblastoma and colon cancer $[64,65]$; miR17-92 cluster with B-cell lymphoma, breast, colon, lung, stomach, prostate, and pancreatic cancers [66-68]; miR-21 with hepatocellular and breast cancer $[69,70]$; miR-155 with diffuse large B-cell lymphoma and colorectal cancer $[71,72]$; miR372/miR373 with testicular germ cell tumor [73]; and the miR-200 family with ovarian cancer [74]. In 2008, Mitchell et al. [75] showed that miRNAs may be ideal blood-based cancer biomarkers for three main reasons: 1) Expression of miRNAs is found frequently deregulated in cancer; 2) the expression patterns of miRNAs in cancer appear to be specific; and 3) miRNAs are usually highly stable in tissues fixed with formalin and, possibly, also in plasma or serum.

Based on this evidence as a whole, the expression levels of individual miRNAs and miRNA signatures are now linked to classification and prognosis of several human cancers.

\section{LB technology in the market}

Several companies have been adapting genetic variation identification panels to include LB-based ctDNA as an input option. Boreal Genomics [76], Trovagene [77], RainDance Technologies [78, 79], Inivata [80], and Pathway Genomics [81] are examples of companies working on this technology (Table 1). Another example is Illumina's spin-off Grail that started in 2016 with the aim of developing an LB-based pan-cancer "molecular stethoscope."

\section{Pre-analytical considerations of LB}

In 2013, Messaoudi et al. [82] indicated that one of the main obstacles for the use of cfDNA in clinical 
Table 1: Examples of LB panels in the market

\begin{tabular}{|c|c|c|c|}
\hline Name of Panel & Company & Genes Analyzed & Reference \\
\hline OnTarget & Boreal Genomics & $\begin{array}{l}\text { Can include up to } 100 \text { mutations across } \\
\text { multiple genes (not listed) }\end{array}$ & 76 \\
\hline Trovera & Trovagene & $E G F R, K R A S$, and $B R A F$ & 77 \\
\hline ThunderBolts Cancer Panel & RainDance Technologies & $\begin{array}{l}\text { ABL1, EGFR, GNAQ, KRAS, PTPN11, } \\
\text { RB1, MET, GNAS, ERBB2, AKT1, ALK, } \\
\text { ERBB4, HNF1A, MLH1, RET, APC, EXH2, } \\
\text { HRAS, MPL, SMAD4, ATM, FBXW7, } \\
\text { IDH1, NOTCH1, SMARCB1, SMO, NPM1, } \\
\text { IDH2, FGFR1, BRAF, CDH1, FGFR2, } \\
\text { JAK2, NRAS, SRC, SKT11, PDGFRA, } \\
\text { JAK3, FGFR3, CDKN2A, CSF1R, FLT3, } \\
\text { KDR, PIK3CA, TP53, VHL, PTEN, KIT, } \\
\text { GNA11, and CTNNB1 }\end{array}$ & 78 \\
\hline ThunderBolts Myeloid Panel & RainDance Technologies & $\begin{array}{l}\text { ASXL1, BCOR, BCOR1, BRAF, CALR, } \\
\text { CBL, CBLB, GATA1, FLT3, EZH2, ETV6, } \\
\text { DNMT3A, CSF3R, CEBPA, GATA2, GNAS, } \\
\text { HRAS, IDH1, IDH2, JAK1, JAK2, JAK3, } \\
\text { KDM6A, KIT, KMT2A/MLL-PTD, KRAS, } \\
\text { MEK1, MPL, PTEN, PML, PHF6, NRAS, } \\
\text { NPM1, NOTCH1, MYD88, PTPN11, } \\
\text { RAD21, RUNX1, SETBP1, SF3B1, SMC1A, } \\
\text { MSC3, ZRSR2, WT1, U2AF1, TP53, TET2, } \\
\text { STAG2, and SRSF2 }\end{array}$ & 79 \\
\hline InVision & Inviata & $\begin{array}{l}A K T 1, A L K, B R A F, C C N D 1, C D K N 2 A, \\
C T N N B 1, E G F R, E R B B 2, E S R 1, F G F R 1, \\
F G F R 2, F G F G 3, G A T A 3, G N A 11, G N A Q, \\
G N A S, H R A S, I D H 1, I D H 2, K I T, K R A S, \\
M A P 2 K 1, M E T, M Y C, N F E 2 L 2, N R A S, \\
\text { NTRK1, PDGFRA, PIK3CA, PPP2R1A, } \\
\text { PTEN, STK11, TP53, and U2AF1 }\end{array}$ & 80 \\
\hline $\begin{array}{l}\text { CancerIntercept Detect/ } \\
\text { Monitor }\end{array}$ & Pathway Genomics & $\begin{array}{l}B R A F, C T N N B 1, E G F R, F O X L 2, G N A S, \\
K R A S, N R A S, P I K 3 C A \text {, and TP53 }\end{array}$ & 81 \\
\hline
\end{tabular}

practice is the heterogeneity of the various protocols for the manipulation and analysis of cfDNA. There are complex pre-analytical and analytical considerations to be taken into account when planning cfDNA analyses. Such considerations range from sample collection to interpretation of findings.

Among pre-analytical variables, the blood collection tube used is an important consideration, as it needs to provide the necessary conditions for the stability of the cfDNA [83]. There are several collection tubes on the market as illustrated in Figure 3A. One of the applications in which this is especially critical, because of the need for long-term stable cfDNA, is in studies (such as multicenter clinical trials) in which blood samples are sent for analysis to a laboratory in another region.

Plasma processing is another pre-analytical factor to consider. Messaoudi and colleagues report that performing a double centrifugation during plasma isolation is ideal for minimizing contaminating nuclear DNA from white cells that otherwise would contaminate and dilute true cfDNA [82]. Double centrifugation has thus become the current gold standard for prospective plasma biobanking (Figure 3B).

The choice of procedure for the extraction and purification of cfDNA is, however, the most important pre-analytical factor to be taken into account. For this, a wide variety of kits exist that allow isolating cfDNA from several sources, particularly from plasma. In Figure $3 \mathrm{C}$, some of the popular commercially available kits for the extraction and purification of cfDNA, based on the separation by silica columns or by magnetic beads, are listed. Once the genetic material is isolated, it is necessary to perform an analysis to confirm the quality of the sample. For this, the companies producing the extraction and purification kits offer various quality control methodologies as indicated in Figure 3D. The choice of reagents and equipment to be used will depend to a great extent on availability, accessibility, budget, 
analytical sensitivity, and final readout desired (such as end-point PCR, real-time PCR, digital PCR (dPCR), microarrays, or NGS).

Finally, storage and freezing conditions of ctDNA need to be considered (Figure 3E). Our own data shows that storage at $-20^{\circ} \mathrm{C},-80^{\circ} \mathrm{C}$, and in vapor phase liquid nitrogen (below $-150{ }^{\circ} \mathrm{C}$ ) are equivalent once the DNA has been extracted. Long-term stability of cfDNA in plasma and serum that is frozen prior to extraction remains to be studied.

\section{Analytical possibilities of LB}

The methods for ctDNA analysis can be divided into point mutations analysis; detection of somatic mutations as biomarkers and whole genome analysis (WGA); and detection of rearrangements and chromosomal copynumber changes (Table 2; Figure 3F) [84].

In point mutations analysis, qPCR, dPCR, and targeted sequencing can be included; these technologies are highly sensitive $(<1 \%)$ and allow detection of a low tumor fraction in plasma DNA, while WGA can be used in high tumor fraction situations (sensitivity $>10 \%$ ) [17]. In this sense, the best options for diagnosis are methodologies based on PCR since they allow detection of low levels of ctDNA. NGS methodologies are increasing the sensitivity and throughput necessary for diagnostic ctDNA analysis [85].

\section{Potential limitations of LB}

While LB is doubtlessly an extremely powerful addition to the diagnostic tool set, the approach also suffers from several technology-inherent limitations that need to be discussed and considered.

First, LB may have lower sensitivity than SB for rare variants. This is because LB attempts detection of alterations in peripheral fluids rather than the tumor itself (volume dilution) and in a background of non-altered cfDNA from cellular sources other than the tumor (for example, in a patient with other co-morbidities such as sepsis, abundant cfDNA may be circulating that is derived from non-cancerous cell compartments). Second, while LB may be able to pick up heterogeneity (via ultra-deep NGS of ctDNA), tracing tumor heterogeneity back to multiple simultaneous lesions (e.g., primary vs. multiple metastatic sites) and pinpointing which clones dominate which site may be close to impossible without combining LB with smartly targeted SB procedures. In addition, it is plausible that various distinct lesions in a patient would each shed variable amounts of ctDNA and thus LB would not just be a volume-proportional mixture of contributing lesions (thus making the heterogeneity problem even harder to untangle). Some lesions, e.g., brain metastases, may shed little to no ctDNA into the circulation. Finally, LB could potentially pick up physiologically continuously occurring

\section{Surgical Biopsy vs. Liquid Biopsy}

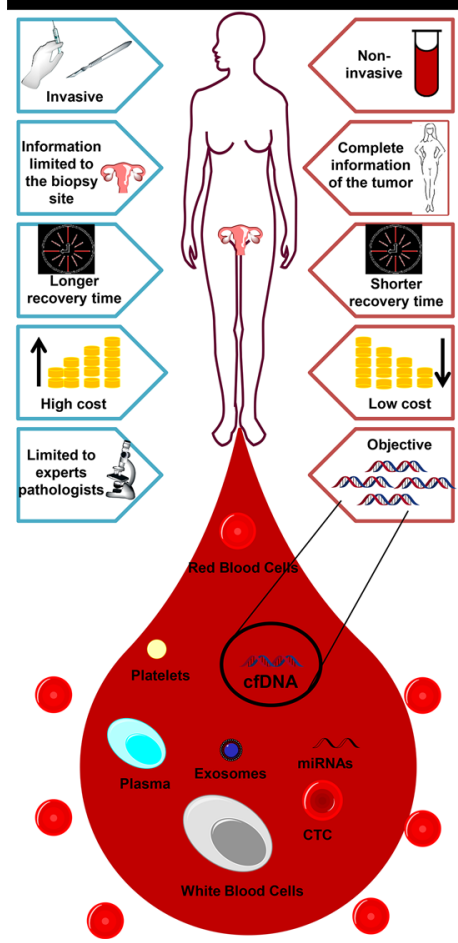

A Plasma Collection

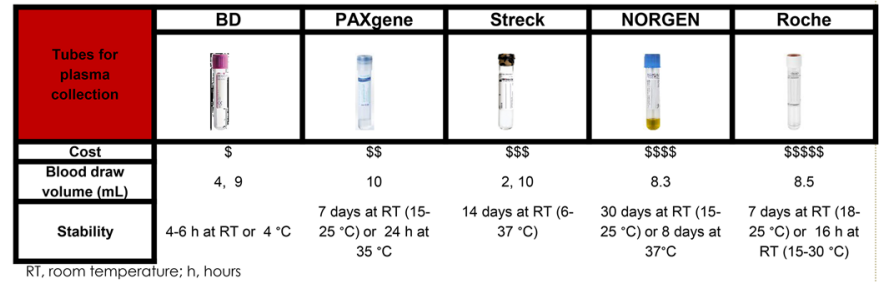

B Plasma procedure
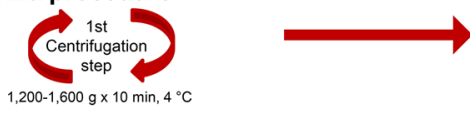

C Extraction and Purification

\begin{tabular}{|c|c|c|c|c|c|c|}
\hline $\begin{array}{l}\text { Kits for } \\
\text { extraction and } \\
\text { purification }\end{array}$ & $\begin{array}{l}\text { MACHEREY- } \\
\text { NAGEL } \\
\text { (NucleoSpin Plasma } \\
\text { XS) }\end{array}$ & $\begin{array}{l}\text { EPIGENTEK } \\
\text { (EpiQuik } \\
\text { Circulating Cell- } \\
\text { Free DNA } \\
\text { Isolation Kit) }\end{array}$ & $\begin{array}{l}\text { Thermo } \\
\text { Fisher } \\
\text { (MagMAX Cell- } \\
\text { Free DNA } \\
\text { Isolation Kit) }\end{array}$ & $\begin{array}{c}\text { Qiagen } \\
\text { (OIAamp } \\
\text { Circulating } \\
\text { Nucleic } \\
\text { Acid Kit) }\end{array}$ & $\begin{array}{c}\text { ZYMO } \\
\text { RESEARCH } \\
\text { (Quick-cfDNA } \\
\text { Serum \& P Plasma } \\
\text { Kit) }\end{array}$ & $\begin{array}{c}\text { NORGEN } \\
\text { (Plasma/Serum } \\
\text { Cell-Free } \\
\text { Circulating DNA } \\
\text { Purification) }\end{array}$ \\
\hline $\begin{array}{l}\text { Type of } \\
\text { separation }\end{array}$ & & & & & $\theta$ & 7 \\
\hline Cost & $\$$ & $\$ \$$ & $\$ \$ \$$ & $\$ \$ \$$ & $\$ \$ \$ \$ \$$ & $\$ \$ \$ \$ \$ \$$ \\
\hline $\begin{array}{c}\text { Reactions per } \\
\text { kit }\end{array}$ & 10,250 & 50 & 25,50 & 50 & 50 & $10,20,50$ \\
\hline $\begin{array}{l}\text { Input volume of } \\
\text { plasma (mL) }\end{array}$ & $0.2-0.72$ & $0.1-1$ & $0.5-10$ & $1-5$ & $0.2-10$ & $0.010-10$ \\
\hline $\begin{array}{c}\text { Elution volume } \\
(\mu L)\end{array}$ & $5-30$ & 20 & $15-50$ & $20-150$ & $\geq 50$ & $25-100$ \\
\hline
\end{tabular}

D Quantification

$>2100$ Bioanalyzer

KNA Quantification

$>$ NanoDrop 2000

(Thermo Fisher)

$>$ Quant-iT TM Pico
Green dsDNA Assay

Kit (Thermo Fisher)
Kissa

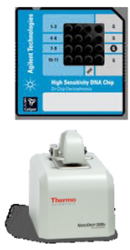

$>\mathrm{QPCR}$

E cfDNA Storage

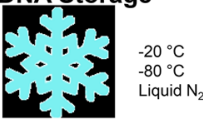

F Detection Technologies for cfDNA

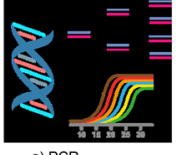

a) PCR

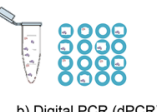

b) Digital PCR (dPCR)

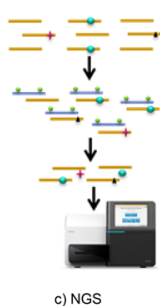

Figure 3: Comparison of features between surgical (tissue-based) and liquid biopsies (left) and overview of the various elements of the liquid biopsy workflow (A-F, right). 
Table 2: Comparison of methodologies for ctDNA analysis

\begin{tabular}{llll}
\hline Method & Technology & Sensitivity & Type of Alteration \\
\hline qPCR & ARMS-Scorpions PCR & $0.05-0.1 \%$ & Known point mutation \\
& Clamping PCR & $0.1-1 \%$ & \\
Digital PCR & TaqMan & $0.1-1 \%$ & \\
Beaming & $0.01 \%$ & \\
Target sequencing & ddPCR & $0.001 \%$ & Point mutations in gene \\
& TAm-Seq & $>2 \%$ & regions; structural alterations \\
\multirow{2}{*}{ Whole genome sequencing } & $0.1 \%$ & in gene regions \\
& SAFE-SeqS & $0.01 \%$ & Genome-wide copy-number \\
& CAPP-Seq & $0.001 \%$ & changes; personalized \\
& Digital karyotyping & & genome-wide rearrangements \\
\hline
\end{tabular}

ARMS, amplification refractory mutation system; BEAMing, beads, emulsion, amplification, magnetics; CAPP-Seq, cancer personalized profiling by deep sequencing; ddPCR, droplet digital PCR; PARE, parallel analysis of RNA ends; qPCR, quantitative PCR; SAFE-SeqS, safe-sequencing system; TAm-Seq, tagged-amplicon deep sequencing.

but clinically inconsequential mutational events in other high turnover compartments, such as the bone marrow. This would further complicate the interpretation of rare alleles detected by ultra-deep sequencing of ctDNA.

\section{Evolutional analysis of cancer by ctDNA}

Besides the benefits mentioned previously, LB may also allow for evolutional analysis of cancer in real time. The subclonal dynamics of ctDNA has been characterized in several studies, which demonstrate that ctDNA can be used to detect emergence of resistance to treatment [86-88]. LB has allowed to carry out studies on frequency, identity, and evolution of subclonal genetic alterations that had previously been very limited due to the difficulty of serially accessing tumor tissue [88, 89]. Abbosh et. al. performed a a phylogenetic subclone analysis in NSCLC employing ctDNA over a period of 231 days and identified single nucleotide variations (SNV) that had not been identified in the primary tumor, suggesting that ctDNA can be used when subclones of the primary tumor are found in low quantities. In addition they analyzed patients who had liver metastases in which subclones were identified originating in the primary pulmonary tumor [88]. Furthermore, they were able to associate the ctDNA with the histological type of the tumor. Imamura et. al. determined that ctDNA is a specific tumor marker for assessing the response to treatment and the molecular dynamics of NSCLC-related oncogenes [90].

\section{Summary}

LB is at the dawn of a new era of cancer "theranostics", being a non-invasive addition to SB. LB is capable of generating valuable information about cancer almost in real time that can be used to reveal the genetic features of individual tumors, thus improving early detection, prognostication, and monitoring treatment responses and eventual resistance. We have reviewed the current state of the art of LB-related analytics and provide an outlook of its clinical utility.

\section{Author contributions}

Irma Guadalupe Domínguez-Vigil: Conceptualization, writing - review and editing. Ana Karen Moreno-Martínez: Writing - review and editing. Julia Y. Wang: Writing - review and editing. Michael H. A. Roehrl: Writing review and editing, funding acquisition, and responsible for the overall content. Hugo Alberto Barrera-Saldaña: Conceptualization, writing - review and editing, funding acquisition, and responsible for the overall content.

\section{ACKNOWLEDGMENTS}

The authors thank Victor Hugo Barajas Olmos for structural design of this review and Sergio LozanoRodriguez, M.D., and Michael Dean, Ph.D., for their critical reading of the manuscript.

\section{CONFLICT OF INTEREST}

The authors have no disclosures.

\section{FUNDING}

This work was supported by the CONACYT's Great National Health Problems Grant (\#247850) to HABS. MHAR acknowledges research funding from Memorial Sloan Kettering Cancer Center, the Farmer Family Foundation, and the Parker Institute for Cancer 
Immunotherapy. This research was funded in part through the NIH/NCI Cancer Center Support Grant P30 CA008748.

\section{REFERENCES}

1. National Cancer Institute. Definition of liquid biopsy - NCI Dictionary of Cancer Terms - National Cancer Institute.

2. Mandel P, Metais P. [Les acides nucléiques du plasma sanguin chez l'homme]. [Article in French]. C R Seances Soc Biol Fil. 1948; 142:241-3.

3. McLarty JL, Yeh CH. Circulating cell-free DNA: The blood biopsy in cancer management. Cell Sci Rep. 2015; 2:00021.

4. Cell-free DNA screening for fetal aneuploidy. Obs Gynecol. 2015; 126: e31-e37.

5. Osborne CM, Hardisty E, Devers P, Kaiser-Rogers K, Hayden MA, Goodnight W, Vora NL. Discordant noninvasive prenatal testing results in a patient subsequently diagnosed with metastatic disease. Prenat Diagn. 2013; 33:609-11.

6. Stratton MR, Campbell PJ, Futreal PA. The cancer genome. Nature. 2009; 458:719-24.

7. Russo A, Rolfo C, Passigliia F, Rosell R. Targeted Therapies for Non-Small Cell Lung Cancer. In: Russo A, Rosell R, Rolfo C, Editors. Targeted Therapies for Solid Tumors: A Handbook for Moving Toward New Frontiers in Cancer Treatment. New York: Humana Press; 2015. pp. 89-101.

8. Meldrum C, Doyle MA, Tothill RW. Next-Generation Sequencing for Cancer Diagnostics: a Practical Perspective. Clin Biochem Rev. 2011; 32:177-95.

9. The Cancer Genome Atlas Research Network. Comprehensive genomic characterization defines human glioblastoma genes and core pathways. Nature. 2008; 455:1061-8

10. The Cancer Genome Atlas Research Network. Integrated genomic analyses of ovarian carcinoma. Nature. 2011; 474:609-15.

11. The Cancer Genome Atlas Research Network. Integrated genomic characterization of endometrial carcinoma. Nature. 2013; 497:67-73

12. The Cancer Genome Atlas Research Network. Comprehensive molecular profiling of lung adenocarcinoma. Nature. 2014; 511:543-50.

13. Chin EL, da Silva C, Hegde M. Assessment of clinical analytical sensitivity and specificity of next-generation sequencing for detection of simple and complex mutations. BMC Genet. 2013; 14:6.

14. Ko J, Carpenter E, Issadore D. Detection and isolation of circulating exosomes and microvesicles for cancer monitoring and diagnostics using micro-/nano-based devices. Analyst. 2015; 141:450-60.

15. Kerick M, Isau M, Timmermann B, Sültmann H, Herwig R, Krobitsch S, Schaefer G, Verdorfer I, Bartsch G, Klocker $\mathrm{H}$, Lehrach H, Schweiger R. Targeted high throughput sequencing in clinical cancer Settings: formaldehyde fixed- paraffin embedded (FFPE) tumor tissues, input amount and tumor heterogeneity. BMC Med Genomics. 2011; 4: 68.

16. Cree IA. Liquid biopsy for cancer patients: Principles and practice. Pathogenesis. 2015; 2:1-4.

17. Heitzer E, Ulz P, Geigl JB. Circulating tumor DNA as a liquid biopsy for cancer. Clin Chem. 2015; 61:112-23.

18. Lewis AR, Valle JW, McNamara MG. Pancreatic cancer: Are "liquid biopsies" ready for prime-time? World J Gastroenterol. 2016; 22:7175-85.

19. Rolfo C, Castiglia M, Hong D, Alessandro R, Mertens I, Baggerman G, Zwaenepoel K, Gil-Bazo I, Passiglia F, Carreca AP, Taverna S, Vento R, Santini D, et al. Liquid biopsies in lung cancer: The new ambrosia of researchers. Biochim Biophys Acta. 2014; 1846:539-46.

20. Crowley E, Di Nicolantonio F, Loupakis F, Bardelli A. Liquid biopsy: Monitoring cancer-genetics in the blood. Nat Rev Clin Oncol. 2013; 10:472-84.

21. Diaz LA, Bardelli A. Liquid biopsies: Genotyping circulating tumor DNA. Journal of Clinical Oncology. 2014; 32:579-86.

22. Wan JC, Massie C, Garcia-Corbacho J, James D, Caldas C, Pacey S, Baird R, Rosenfeld N. Liquid biopsies come of age: Towards implementation of circulating tumour DNA. Nat Rev Cancer. 2017; 17:223-38.

23. Zheng D, Ye X, Zhang MZ, Sun Y, Wang JY, Ni J, Zhang HP, Zhang L, Luo J, Zhang J, Tang L, Su B, Chen G, et al. Plasma EGFR T790M ctDNA status is associated with clinical outcome in advanced NSCLC patients with acquired EGFR-TKI resistance. Sci Rep. 2016; 6:20913.

24. Novello S, Barlesi F, Califano R, Cufer T, Ekman S, Levra MG, Kerr K, Popat S, Reck M, Senan S, Simo GV, Vansteenkiste J, Peters S. Metastatic non-small-cell lung cancer: ESMO Clinical Practice Guidelines for diagnosis, treatment and follow-up. Ann Oncol. 2016; 27(Suppl 5): v1-v27.

25. Stroun M, Maurice P, Vasioukhin V, Lyautey J, Lederrey C, Lefort F, Rossier A, Chen XQ, Anker P. The origin and mechanism of circulating DNA. Ann NY Acad Sci. 2000; 906:161-8.

26. Alix-Panabières C, Pantel K. Clinical applications of circulating tumor cells and circulating tumor DNA as liquid biopsy. Cancer Discov. 2016; 6:479-91.

27. Schwarzenbach H, Hoon DS, Pantel K. Cell-free nucleic acids as biomarkers in cancer patients. Nat Rev Cancer. 2011; 11:426-37.

28. Cheng F, Su L, Qian C. Circulating tumor DNA: a promising biomarker in the liquid biopsy of cancer. Oncotarget. 2016; 7:48832-41. https://doi.org/10.18632/ oncotarget.9453.

29. Li J, Dittmar RL, Xia S, Zhang H, Du M, Huang CC, Druliner BR, Boardman L, Wang L. Cell-free DNA copy number variations in plasma from colorectal cancer patients. Mol Oncol. 2017; 11:1099-111.

30. Soave A, Chun FK, Hillebrand T, Rink M, Weisbach L, Steinbach B, Fisch M, Pantel K, Schwarzenbach H. 
Copy number variations of circulating, cell-free DNA in urothelial carcinoma of the bladder patients treated with radical cystectomy: A prospective study. Oncotarget. 2017; 8:56398-407. https://doi.org/10.18632/ oncotarget.17657.

31. Husain H, Nykin D, Bui N, Quan D, Gomez G, Woodward B, Venkatapathy S, Duttagupta R, Fung E, Lippman SM, Kurzrock R. Cell-free DNA from ascites and pleural effusions: Molecular insights into genomic aberrations and disease biology. Mol Cancer Ther. 2017; 16:948-55.

32. Li Z, Guo X, Tang L, Peng L, Chen M, Luo X, Wang S, Xiao Z, Deng Z, Dai L, Xia K, Wang J. Methylation analysis of plasma cell-free DNA for breast cancer early detection using bisulfite next-generation sequencing. Tumour Biol. 2016; 37:13111-9.

33. Fleischhacker M, Schmidt B. Circulating nucleic acids (CNAs) and cancer-A survey. Biochim Biophys Acta. 2007; 1775:181-232.

34. Siravegna G, Bardelli A. Genotyping cell-free tumor DNA in the blood to detect residual disease and drug resistance. Genome Biol. 2014; 15:449.

35. Diehl F, Li M, Dressman D, He Y, Shen D, Szabo S, Diaz LA Jr, Goodman SN, David KA, Juhl H, Kinzler KW, Vogelstein B. Detection and quantification of mutations in the plasma of patients with colorectal tumors. Proc Natl Acad Sci U S A. 2005; 102:16368-73.

36. Bettegowda C, Sausen M, Leary RJ, Kinde I, Wang Y, Agrawal N, Bartlett BR, Wang H, Luber B, Alani RM, Antonarakis ES, Azad NS, Bardelli A, et al. Detection of circulating tumor DNA in early- and late-stage human malignancies. Sci Transl Med. 2014; 6:224ra24.

37. Ashworth TR. A case of cancer in which cells similar to those in the tumors were seen in the blood after death. The Australian Medical Journal. 1869; 14:146-9.

38. Lianidou ES, Strati A, Markou A. Circulating tumor cells as promising novel biomarkers in solid cancers. Crit Rev Clin Lab Sci. 2014; 51:160-71.

39. Pantel K, Alix-Panabières C. Detection methods of circulating tumor cells. J Thorac Dis. 2012; 4:446-7.

40. Park Y, Kitahara T, Urita T, Yoshida Y, Kato R. Expected clinical applications of circulating tumor cells in breast cancer. World J Clin Oncol. 2011; 2:303-10.

41. CellSearch. CellSearch Circulating Tumor Cell Kit (Epithelial) User's Guide. 2013.

42. Brock G, Castellanos-Rizaldos E, Hu L, Coticchia C, Skog J. Liquid biopsy for cancer screening, patient stratification and monitoring. Transl Cancer Res. 2015; 4:280-90.

43. Pantel K, Alix-Panabières C. Cell lines from circulating tumor cells. Oncoscience. 2015; 2:1-2. https://doi. org/10.18632/oncoscience.195.

44. Kolostova K, Spicka J, Matkowski R, Bobek V. Isolation, primary culture, morphological and molecular characterization of circulating tumor cells in gynecological cancers. Am J Transl Res. 2015; 7:1203-13.
45. Kolostova K, Zhang Y, Hoffman RM, Bobek V. In vitro culture and characterization of human lung cancer circulating tumor cells isolated by size exclusion from an orthotopic nude-mouse model expressing fluorescent protein. J Fluoresc. 2014; 24:1531-6.

46. Maheswaran S, Haber DA. Ex vivo culture of CTCs: An emerging resource to guide cancer therapy. Cancer Res. 2015; 75:2411-5.

47. Valadi H, Ekström K, Bossios A, Sjöstrand M, Lee JJ, Lötvall JO. Exosome-mediated transfer of mRNAs and microRNAs is a novel mechanism of genetic exchange between cells. Nat Cell Biol. 2007; 9:654-9.

48. Lin J, Li J, Huang B, Liu J, Chen X, Chen XM, Xu YM, Huang LF, Wang XZ. Exosomes: Novel Biomarkers for Clinical Diagnosis. Sci World J. 2015; 2015:657086.

49. Sheridan C. Exosome cancer diagnostic reaches market. Nat Biotechnol. 2016; 34:359-60.

50. Vanni I, Alama A, Grossi F, Dal Bello MG, Coco S. Exosomes: A new horizon in lung cancer. Drug Discov Today. 2017; 22:927-36.

51. Witwer KW, Buzás EI, Bemis LT, Bora A, Lässer C, Lötvall J, Nolte-'t Hoen EN, Piper MG, Sivaraman S, Skog J, Théry C, Wauben MH, Hochberg F. Standardization of sample collection, isolation and analysis methods in extracellular vesicle research. J Extracell Vesicles. 2013; 2:20360.

52. Melo SA, Luecke LB, Kahlert C, Fernandez AF, Gammon ST, Kaye J, LeBleu VS, Mittendorf EA, Weitz J, Rahbari N, Reissfelder C, Pilarsky C, Fraga MF, et al. Glypican-1 identifies cancer exosomes and detects early pancreatic cancer. Nature. 2015; 523:177-82.

53. An M, Lohse I, Tan Z, Zhu J, Wu J, Kurapati H, Morgan MA, Lawrence TS, Cuneo KC, Lubman DM. Quantitative proteomic analysis of serum exosomes from patients with locally advanced pancreatic cancer undergoing chemoradiotherapy. J Proteome Res. 2017; 16:1763-72.

54. Ning K, Wang T, Sun X, Zhang P, Chen Y, Jin J, Hua D. UCH-L1-containing exosomes mediate chemotherapeutic resistance transfer in breast cancer. J Surg Oncol. 2017; 115:932-40.

55. Pan L, Liang W, Fu M, Huang ZH, Li X, Zhang W, Zhang P, Qian H, Jiang PC, Xu WR, Zhang X. Exosomes-mediated transfer of long noncoding RNA ZFAS1 promotes gastric cancer progression. J Cancer Res Clin Oncol. 2017; 143:991-1004.

56. Tsukamoto M, Iinuma H, Yagi T, Matsuda K, Hashiguchi Y. Circulating exosomal microRNA-21 as a biomarker in each tumor stage of colorectal cancer. Oncology. 2017; 92:360-70.

57. Hu Y, Li D, Wu A, Qiu X, Di W, Huang L, Qiu L. TWEAKstimulated macrophages inhibit metastasis of epithelial ovarian cancer via exosomal shuttling of microRNA. Cancer Lett. 2017; 393:60-7.

58. Frontela Noda M. [MicroRNAs in cancer: from research to clinical practice]. [Article in Spanish]. Rev Cubana Med. 2012; 51:325-35. 
59. Etheridge A, Lee I, Hood L, Galas D, Wang K. Extracellular microRNA: A new source of biomarkers. Mutat Res. 2011; 717:85-90.

60. Resnick KE, Alder H, Hagan JP, Richardson DL, Croce CM, Cohn DE. The detection of differentially expressed microRNAs from the serum of ovarian cancer patients using a novel real-time PCR platform. Gynecol Oncol. 2009; 112:55-9.

61. Xie P, Li X, Tan X, Sun X, Wang C, Yu J. Sequential serum let-7 is a novel biomarker to predict accelerated reproliferation during fractional radiotherapy in lung cancer. Clin Lung Cancer. 2016; 17: e95-e101.

62. Shen LQ, Xie YZ, Qian XF, Zhuang ZX, Jiao Y, Qi XF. A single nucleotide polymorphism in the promoter region of let-7 family is associated with lung cancer risk in Chinese. Genet Mol Res. 2015; 14:4505-12.

63. Cimmino A, Calin GA, Fabbri M, Iorio MV, Ferracin M, Shimizu M, Wojcik SE, Aqeilan RI, Zupo S, Dono M, Rassenti L, Alder H, Volinia S, et al. miR-15 and miR-16 induce apoptosis by targeting BCL2. Proc Natl Acad Sci U S A. 2005; 102:13944-9.

64. Welch C, Chen Y, Stallings RL. MicroRNA-34a functions as a potential tumor suppressor by inducing apoptosis in neuroblastoma cells. Oncogene. 2007; 26:5017-22.

65. Tazawa H, Tsuchiya N, Izumiya M, Nakagama H. Tumorsuppressive miR-34a induces senescence-like growth arrest through modulation of the E2F pathway in human colon cancer cells. Proc Natl Acad Sci U S A. 2007; 104:15472-7.

66. Mendell JT. miRiad roles for the miR-17-92 cluster in development and disease. Cell. 2008; 133:217-22.

67. Hayashita Y, Osada H, Tatematsu Y, Yamada H, Yanagisawa K, Tomida S, Yatabe Y, Kawahara K, Sekido Y, Takahashi T. A polycistronic microRNA cluster, miR-17-92, is overexpressed in human lung cancers and enhances cell proliferation. Cancer Res. 2005; 65:9628-32.

68. He L, Thomson JM, Hemann MT, Hernando-Monge E, Mu D, Goodson S, Powers S, Cordon-Cardo C, Lowe SW, Hannon GJ, Hammond SM. A microRNA polycistron as a potential human oncogene. Nature. 2005; 435:828-33.

69. Meng F, Henson R, Wehbe-Janek H, Ghoshal K, Jacob ST, Patel T. MicroRNA-21 regulates expression of the PTEN tumor suppressor gene in human hepatocellular cancer. Gastroenterology. 2007; 133:647-58.

70. Frankel LB, Christoffersen NR, Jacobsen A, Lindow M, Krogh A, Lund AH. Programmed cell death 4 (PDCD4) is an important functional target of the microRNA miR-21 in breast cancer cells. J Biol Chem. 2008; 283:1026-33.

71. Zhu FQ, Zeng L, Tang N, Tang YP, Zhou BP, Li FF, Wu WG, Zeng XB, Peng SS. MicroRNA-155 downregulation promotes cell cycle arrest and apoptosis in diffuse large B-cell lymphoma. Oncol Res. 2016; 24:415-27.

72. Zhang XF, Tu R, Li K, Ye P, Cui X. Tumor suppressor PTPRJ is a target of miR-155 in colorectal cancer. J Cell Biochem. 2017; 118:3391-400.
73. Voorhoeve PM, le Sage C, Schrier M, Gillis AJ, Stoop H, Nagel R, Liu YP, van Duijse J, Drost J, Griekspoor A, Zlotorynski E, Yabuta N, De Vita G, et al. A genetic screen implicates miRNA-372 and miRNA-373 as oncogenes in testicular germ cell tumors. Cell. 2006; 124:1169-81.

74. Kan CW, Hahn MA, Gard GB, Maidens J, Huh JY, Marsh DJ, Howell VM. Elevated levels of circulating microRNA-200 family members correlate with serous epithelial ovarian cancer. BMC Cancer. 2012; 12:627.

75. Mitchell PS, Parkin RK, Kroh EM, Fritz BR, Wyman SK, Pogosova-Agadjanyan EL, Peterson A, Noteboom J, O'Briant KC, Allen A, Lin DW, Urban N, Drescher CW, et al. Circulating microRNAs as stable blood-based markers for cancer detection. Proc Natl Acad Sci U S A. 2008; 105:10513-8.

76. Boreal Genomics. OnTarget Mutation Detection Panels. 2017.

77. Trovagene Diagnostics. Trovera. 2017.

78. RainDance Technologies. ThunderBolts Cancer Panel. 2017.

79. RainDance Technologies. ThunderBolts Myeloid Panel. 2017.

80. Inviata. Invision. 2017.

81. Pathway Genomics. Cancer Monitoring Liquid Biopsy Blood Testing. 2017.

82. El Messaoudi S, Rolet F, Mouliere F, Thierry AR. Circulating cell free DNA: Preanalytical considerations. Clin Chim Acta. 2013; 424:222-30.

83. Spindler KL. Methodological, biological and clinical aspects of circulating free DNA in metastatic colorectal cancer. Acta Oncol (Madr). 2017; 56:7-16.

84. Haber D, Velculescu V. Blood-based analysis of cancer: Circulating tumor cells and circulating tumor DNA. Cancer Discov. 2014; 4:650-61.

85. He Q, Johnston J, Zeitlinger J, City K, City K. Liquid biopsies: Genotyping circulating tumor DNA. J Clin Oncol. 2015; 33:395-401.

86. Wang W, Song Z, Zhang Y. A comparison of ddPCR and ARMS for detecting EGFR T790M status in ctDNA from advanced NSCLC patients with acquired EGFR-TKI resistance. Cancer Med. 2017; 6:154-62.

87. Imamura F, Uchida J, Kukita Y, Kumagai T, Nishino K, Inoue T, Kimura M, Oba S, Kato K. Monitoring of treatment responses and clonal evolution of tumor cells by circulating tumor DNA of heterogeneous mutant EGFR genes in lung cancer. Lung Cancer. 2016; 94:68-73.

88. Abbosh C, Birkbak NJ, Wilson GA, Jamal-Hanjani M, Constantin T, Salari R, Le Quesne J, Moore DA, Veeriah S, Rosenthal R, Marafioti T, Kirkizlar E, Watkins TB, et al. Phylogenetic ctDNA analysis depicts early stage lung cancer evolution. Nature. 2017; 545:446-51.

89. Landau DA, Carter SL, Stojanov P, McKenna A, Stevenson K, Lawrence MS, Sougnez C, Stewart C, Sivachenko A, Wang L, Wan Y, Zhang W, Shukla SA, et al. Evolution 
and impact of subclonal mutations in chronic lymphocytic leukemia. Cell. 2013; 152:714-26.

90. Imamura $\mathrm{T}$, Komatsu $\mathrm{S}$, Ichikawa $\mathrm{D}$, Kawaguchi $\mathrm{T}$, Miyamae M, Okajima W, Ohashi T, Arita T, Konishi
H, Shiozaki A, Morimura R, Ikoma H, Okamoto K, et al. Liquid biopsy in patients with pancreatic cancer: Circulating tumor cells and cell-free nucleic acids. World J Gastroenterol. 2016; 22:5627-41. 